\title{
Visceral Adiposity index and atherogenic index of plasma as reliable indices to prediction of cardiovascular diseases in adults: A Cross-Sectional analysis from the Iranian RaNCD Cohort Data
}

\author{
Behrooz Hamzeh \\ Kermanshah University of Medical Sciences \\ Yahya Pasdar \\ Kermanshah University of Medical Sciences \\ Narmin Mirzaei \\ Kermanshah University of Medical Sciences \\ Roya Safari Faramani \\ Kermanshah University of Medical Sciences \\ Farid Najafi \\ Kermanshah University of Medical Sciences \\ Ebrahim Shakiba \\ Kermanshah University of Medical Sciences \\ Mitra Darbandi ( $\sim$ m.darbandi@kums.ac.ir) \\ Kermanshah University of Medical Sciences
}

\section{Research Article}

Keywords: Cardiovascular diseases, Body Mass Index, Primary Prevention, Cholesterol, Obesity

Posted Date: February 26th, 2021

DOI: https://doi.org/10.21203/rs.3.rs-241633/v1

License: (a) This work is licensed under a Creative Commons Attribution 4.0 International License. Read Full License 


\section{Abstract}

Background: Visceral Adiposity index (VAI) and atherogenic index of plasma (AIP) are relatively new indicators for predicting Non-Communicable disease (NCDs). The aim of this study was to assess the association AIP and VAI with risk of developing cardiovascular diseases (CVDs) in adults.

Materials: This was a cross-sectional analysis conducted on 7362 individuals aged 35 to65 years participated in Ravansar Non-Communicable Diseases (RaNCD) cohort study. AIP was calculated based on the value of TG and HDL-C. VAI was calculated using BMI (Body mass index), waist circumference (WC), serum triglyceride, and High density lipoprotein cholesterol (HDL-C).All participants were stratified into three groups based on AIP and VAI tertiles. Simple and multiple logistic regression models were applied to assess the effect of these indices on CVDs.

Results: The mean of AIP and VAI was significantly higher in CVDs patients than in non-CVDs $(P<0.001)$. After adjusting for age, sex hypertension, hyperlipidemia and smoking the risk of CVDs in the second and third tertile of AIP were 1.27 (95\% Cl: 1.06, 1.52) and $1.63(95 \% \mathrm{Cl}: 1.31,2.03)$ times higher comparing to the first tertile, respectively. Risk of CVDs in the second and third tertile of VAl were1.41 (95\% Cl: 1.18, 1.70) and 1.98 (95\% Cl: 1.60 , 2.46) times higher than the first tertile, respectively; while adjusting for age, sex, hypertension and dyslipidemia.

Conclusion: According to the findings, AIP and VAI were positively associated with CVDs in adults. Therefore, AIP and VAI can be useful in identifying high-risk subgroups of CVDs in general population.

\section{Background}

Cardiovascular diseases (CVDs) are the leading cause of mortality worldwide. According to the global burden of diseases (GBD), CVDs are the cause of 17.9 million deaths in 2017, of which more than three-quarters were in lowand middle-income countries[1]. Approximately $50 \%$ of annual deaths and $50 \%$ of deaths caused by noncommunicable diseases (NCDs) are due to CVDs in Iran [2].

In addition to genetic factors, there are several known risk factors for CVDs event, including hypertension; dyslipidemia, obesity, and smoking, some of these factors are almost preventable and easy to change[3]. Reducing blood pressure and serum cholesterol can, indeed, effectively prevent or delay CVDs events[4].Thus, measuring the risk factors for prediction and early detection of disease can be useful. In a meta-analysis study (2020), CVDs prediction was reported based on simple anthropometric indices including waist circumference (WC), body mass index (BMI) and waist to hip ratio (WHR) [5].Accumulation of visceral fat and blood lipid also are among the numerous risk factors contributing to $\operatorname{CVDs}[6,7]$.

Amato et al. (2010) introduced visceral adiposity index (VAl), which is a combination of WC, BMI, triglyceride (TG) and high-density lipoprotein cholesterol (HDL-C) [8]. VAl is a reliable index for the function of visceral fat in the body. Previous studies have confirmed the accuracy of VAI for predicting NCDs including metabolic syndrome (MetS), type 2 diabetes mellitus (T2DM) and hypertension [9-11].

Among the biochemical indicators that represent the status of blood lipids, the atherogenic index of plasma (AIP) is the logarithmic conversion of the TG to HDL-C ratio, a strong predictor of atherosclerosis and CVDs. In addition, AIP correlates with lipoprotein particle size (HDL, LDL, VLDL), which act as the most sensitive CVDs markers. Studies have also identified it as a reliable and accurate predictor of heart attack and atherosclerosis [12-14]. AIP is the best determinant for fractionated esterification rate of HDL-C and more useful than routine lipid markers. 
Previous research has shown that the average of these two indices is different in different populations; the mean of AIP is between 0.17 to $0.41[13,15]$ and the mean of VAl is between 2.1 to 3.2 in Iranian populations [16-18]. The difference in the averages of these indexes indicates the need for further studies in different populations and ethnicities. Thus, using accurate and low-cost indicators is useful to evaluate the risk factors of CVDs and its prediction. Therefore, this study aimed to assess the association of AIP and VAI with CVDs in adults using the Iranian Ravansar Non-Communicable Diseases (RaNCD) Cohort Data.

\section{Methods}

\section{Study design and participants}

This is a cross-sectional analysis of the Ravansar Non-Communicable disease (RaNCD) cohort study. The RaNCD study is one out of the seventeen sites of prospective epidemiological research study in Iran (PERSIAN). Ravansar is a district with a population of about 50,000 people, located in western Iran and in Kermanshah province. The number of participants in the baseline phase of the RaNCD was 10,000 adults, who all of whom were permanent residents of Ravansar. Details of the RaNCD methodology has been described elsewhere[19].

All subjects in the initial phase of RaNCD entered the present study. According to the objectives of the present study, subjects with cancer $(n=85)$, renal failure $(n=64)$, kidney stones $(n=1794)$, pregnant woman $(n=138)$ and cases with missed information $(n=638)$ were excluded from the study due to drug interactions and their effect on the occurrence of CVDs; as well as anthropometric changes, especially in pregnant women.

\section{Data collection}

All interviews were conducted by trained and face-to-face individuals at the RaNCD cohort Study Center. Demographic information including age, sex, marital status, level of education, place of residence (urban, rural), history of chronic diseases, smoking and alcohol consumption were recorded online in an electronic data collection form. Biochemical parameters, anthropometric indices and blood pressure were measured according to the cohort protocol.

Persian cohort physical activity questionnaire was used to assess physical activity in participants. This questionnaire included 22 questions about the amount of different daily activities of the subjects during the day; the answers to these questions were recorded in hours or minutes per day in the questionnaire. Finally, the questionnaire information was extracted and used based on met/ hour per day.

\section{Biochemical and anthropometric measurements}

To measure biochemical markers including TG and HDL-C, blood samples were collected after a 12 hours fasting. AIP was calculated by using the following formula: $\log _{10}$ (TG/HDL-C)[14]; and can be classified based on the values obtained: -0.3 to 0.1 for low risk, 0.1 to 0.24 for moderate, and more than 0.24 for high risk of CVDs[20].

Body weight was measured using Bio-Impedance Analyzer BIA (Inbody 770, Inbody Co, Seoul, Korea) with a precision of $0.5 \mathrm{~kg}$. Other anthropometric measurements including body fat mass (BFM), percent body fat (BF \%), skeletal muscle mass (SLM) and visceral fat area (VFA) were also measured with BIA. The height of the participants were measured with BSM 370 (Biospace Co, Seoul, Korea) with a precision of $0.1 \mathrm{~cm}$. BM/ was 
calculated weight $(\mathrm{kg})$ divided by the square of height $(\mathrm{m})$. WC was measured with a flexible measuring tape at a level midway between the lower rib margin and the iliac crest to the nearest $0.5 \mathrm{~cm}$. VAl was measured by

Males: $\mathrm{VAI}=\left(\frac{W C}{39.68+(1.88 \times B M I)}\right) \times\left(\frac{T G}{1.03}\right) \times\left(\frac{1.31}{H D L}\right)$

Females: $\mathrm{VAI}=\left(\frac{W C}{39.58+(1.89 \times B M I)}\right) \times\left(\frac{T G}{0.81}\right) \times\left(\frac{1.52}{H D L}\right)$

\section{Definition}

CVDs: According to the RaNCD cohort study protocol, CVDs cases were those have a history of hospitalization and / or treatment of one or more heart conditions including stroke, Myocardial infarction (MI) and coronary artery disease (CAD), and / or current use of medication for CVDs.

Hypertension: Cases with $\mathrm{SBP} \geq 140$ and $\mathrm{DBP} \geq 90$ or current use of medication for hypertension. Hyperlipidemia: Cases that are currently taking medication for lipid disorders.

Obesity: Individuals with the BMI over 30 were considered obese.

\section{Data analysis}

Data analysis was performed using Stata version 14.1 software (Stata Corp, College Station, TX, USA). Findings from continues variables are presented as mean \pm standard deviation and categorical variables as frequency (percent). The normality of the data was assessed by Kolmogorov-Smirnov test. According to the binary outcome (CVDs), we used simple and multiple logistic regression models to assess the effect of AIP and VAI on CVDs separately. Variables with p-value $<0.2$ in univariable analysis were entered into multivariable logistic model. All statistical tests with $95 \%$ confidence interval and $P$ value less than 0.05 were considered as statistically significant.

\section{Results}

Finally, 7362 subjects out of 10081 participants of RaNCD were eligible for data analysis. The baseline demographics, biochemical and anthropometrics characteristics of the participants are shown in table 1.The mean age of the participants was $47.20 \pm 8.33$ years and 3420 (46.45\%) were male. The mean of VAl for participants with CVDs (6.54 \pm 5.31$)$ was significantly higher than participants without CVDs $(4.44 \pm 3.60),(P<0.001)$. The mean AIP in CVDs and non-CVDs groups were $1.07 \pm 0.61$ and $0.94 \pm 0.65$, respectively $(P<0.001)$. The prevalence of MetS in the CVDs group (53.80\%)was significantly higher than the non-CVDs group (20.37\%), $(P<0.001)$.

The mean BMI in tertiles of VAI were $25.82 \pm 4.70,27.75 \pm 4.77$ and $28.40 \pm 4.17 \mathrm{~kg} / \mathrm{m}^{2}$, respectively $(P<0.001)$ in male; also BMI has increased significantly with increasing VAI in female. The mean FBS in tertiles of VAI were $91.33 \pm 24.40,95.94 \pm 28.58$ and $102.54 \pm 34.45 \mathrm{mg} / \mathrm{dl}$, respectively $(P<0.001)$ in male; also FBS has increased significantly with increasing VAI in female. There were significant differences in anthropometric indices including WC and WHR and lipid profile (TG, HDL-C, LDL, TC) between VAl tertiles $(P<0.001)$ in male and female. Participants with higher VAI had significantly more hypertension, dyslipidemia, MetS and CVDs compared to those with low VAI (Table 2). 
The mean WHR in tertiles of AIP were $0.90 \pm 0.06,0.94 \pm 0.06$ and $0.96 \pm 0.06$, respectively $(P<0.001)$ in male. There were significant differences in anthropometric indices and lipid profile between AIP tertiles $(P<0.001)$. Also, participants with higher AIP had significantly more hypertension, dyslipidemia MetS and CVDs compared to those with low AIP (Table 2).

Univariate logistic regression analysis showed that increase of AIP level was associated with an increased risk of CVD. Risk of CVDs in the second tertile and third tertile AIP was $1.39(1.19,1.63)$ and $1.51(1.28,1.76)$ times higher than the first tertile, respectively. In multiple logistic regression analysis and after adjusting for age and sex, an increase of AIP and VAI level was significantly associated with an increased risk of CVDs (Model1). Model 2 shows that after adjusting for age, sex hypertension and hyperlipidemia the risk of CVDs has increased in the third tertile AIP $1.63(1.31,2.03)$ times than first tertile and in the third tertile VAI has increased $1.98(1.60,2.46)$ times than first tertile (Table 3).

Figure 1 schematically shows the increased risk of CVDs with increasing AIP and VAI in participants.

\section{Discussion}

Findings of this study showed that there is a positive association between AIP and VAl with the risk of CVDs in a subgroup of Kurdish adults, and this association remained significant after adjusting for age and sex, hypertension, dyslipidemia and smoking. In addition, males and females with higher VAI and AIP had significantly more hypertension, dyslipidemia, MetS and CVDs compared to those with low VAl and AIP, and also they had higher anthropometric indices, lipid profile and FBS. Thus, AIP and VAI can be used as markers to predict of CVDs. The mean of AIP and VAI in our study was somewhat higher than other studies $[13,15,16]$, which could be due to the studied age group (35-65 years) and the high prevalence of obesity and overweight in participants.

The association between VAI and heart disease has been reported in previous studies; In a cohort study in Greece (2017) has been showed that VAI were independently associated with CVDs [7]. The role of VAI has been assessed in other diseases including T2DM and MetS, which are a risk factor for CVDs; in our study, the risk of T2DM and MetS were increased at higher VAI tertiles. A meta-analysis study (2019) showed that VAI can be an independent predictor to T2DM in Asian populations [21]. Several studies have examined the predictive power of VAI using ROC curve analysis, the results of these studies agree on the accuracy and reliability of VAl for predicting T2DM, hypertension, and MetS $[9,11,22]$. Similar to some studies, in our study, this association was also established in CVDs risk factors; our findings showed participants with higher VAI had significantly more hypertension, dyslipidemia, anthropometric indices (BMI, WHR, WC, BF and BFM) and lipid profiles compared to those with low VAI. In other words, these two indexes are also positively associated with risk factors of CVDs. This association has been reported in other studies; studies in Indonesia and China showed that the risk of T2DM and hypertension increased with increasing VAI level $[10,11]$. A cross- sectional study Showed that an increase in anthropometric indices (BMI and WC) and liver enzymes (ALT and GGT) and LDL-C was associated with an increase in AIP levels [23], which is consistent with the findings of our study. Our findings showed that participants with more visceral fat the more odds to developing CVDs. The mechanism of this association can be expressed in this way that visceral fat is mainly depleted by the portal venous system and then discharged into the liver and leading to insulin resistance (29). On the other hand, excess free fatty acids (FFA) may cause the enhancement of lipid synthesis and gluconeogenesis, as well as insulin resistance, resulting in hyperlipidemia, glucose intolerance, hypertension, and finally atherosclerosis (29). 
In previous studies, a positive association between AIP and CVDs has already been observed in different populations such as postmenopausal women and staff $[12,24]$. Several studies have also shown that AIP has a positive association with non-alcoholic fatty liver disease (NAFLD), advanced subclinical coronary artery disease (CAD), atherosclerosis and obesity; and is a useful and reliable marker for predicting these diseases[6, 23, 25]. A study on 11,495 Chinese has shown a significant and positive linear relationship between AIP and the prevalence of ischemic stroke [5]. Similar to our findings, A study in Malaysia showed that among lipid profile, AIP was more positively correlated with TG and more negatively correlated with HDL-C, thus they consider AIP to be the strongest marker in predicting CVDs risk over other indices [24].

Following the industrialization of societies and the rapid growth of urbanization, the lifestyle of Iranians changed, like all people in the world. In this new style, people tend to consume fast food and high-calorie foods, and on the other hand, due to the mechanization of work, physical activity has been reduced, which has led to an increase in general and central obesity, increased pre-diabetes, T2DM , hypercholesterolemia , hypertension and MetS [26-28]. Considering to the limitations of older indices such as BMI and WC- mentioned in previous studies[29-31] - and the high prevalence of morbidity and mortality related to CVDs and need to a suitable tool to screening it; VAI can be a useful, inexpensive and accurate tool for predicting NCDs, especially CVDs [7].

The most important strength of this study was the use of RaNCD prospective study data. This is the first study about the association of AIP and VAI with CVDs on a large population with Kurdish ethnicity. The large sample size is one of the positive points of this study. The main limitation of this study is its cross-sectional nature, which limits the causal inference of the observed associations.

\section{Conclusion}

Findings of this study showed that there is a positive association between AIP and VAI with the risk of CVDs in adults, and this association remained significant after adjust for age and sex. In addition, participants with higher VAI and AIP had significantly more hypertension, dyslipidemia, MetS and CVD compared to those with low VAI and AIP, and also they had higher anthropometric indices, lipid profile and FBS. Thus, AIP and VAl can be used as markers to predict of CVDs.

According to these findings, for prevention and control of the CVDs risk and early intervention programs including healthy diet, physical activity, not smoking and assess of AIP especially for those who are at risk should be carried out regularly.

\section{Abbreviations}

AIP: Atherogenic index of plasma; BMI: Body mass index; CAD: Coronary artery disease; FFA: Free fatty acids; FFQ: Food frequency questionnaire; FBS: Fasting blood sugar; GBD: Global burden of diseases; NCDs: NonCommunicable disease; CVDs: Cardiovascular diseases; BMI: Body mass index; HTN: Hypertension; HDL-C: High density lipoprotein; IL: Interleukin; hs-CRP: High sensitivity C-reactive protein ; MI: Myocardial infraction; NAFLD: Non-alcoholic fatty liver disease; RaNCD: Ravansar non-communicable diseases; PERSIAN: Prospective epidemiologic research of IRAN; TNF-a: Tumor necrosis factor-a; VAl: Visceral Adiposity index; LDL-C: Low density lipoprotein; TG: Triglyceride; WC: Waist circumference.

\section{Declarations}


Acknowledgments

The authors thank the PERSIAN cohort Study collaborators and of Kermanshah University of Medical Sciences.

\section{Authors' contributions}

$\mathrm{BH}$ and YP generated the initial idea for the study, FN and ESH designed the experiments, MD and RSF carried out all analyses and visualization of the results. MD and NM drafted the manuscript. All authors provided critical input into the interpretation of the results, revisions to the manuscript and approved the final draft.

\section{Funding}

This study was supported by the Kermanshah University of Medical Sciences, Kermanshah, Iran (grant number 990607).

\section{Availability of data and materials}

The data analyzed in the study are available from the corresponding author on reasonable request.

\section{Ethics approval and consent to participate}

All procedures performed in studies involving human participants were in accordance with the ethical standards of the institutional and/or national research committee and with the 1964 Helsinki declaration and its later amendments or comparable ethical standards. The Research and Technology Deputy and the Ethical Committee of Kermanshah University of Medical Sciences have approved the study protocol (Ethical Number:

KUMS.REC.1399.639). Participants were provided with oral and written informed consent. Written informed consent was obtained from all subjects prior to enrollment in the study.

\section{Consent for publication}

$\mathrm{N} / \mathrm{A}$

\section{Conflict of interest}

The authors declare no conflicts of interest.

\section{References}

1. Roth GA, et al. Global, regional, and national age-sex-specific mortality for 282 causes of death in 195 countries and territories, 1980-2017: a systematic analysis for the Global Burden of Disease Study 2017. Lancet. 2018;392(10159):1736-88.

2. Sadeghi M, Haghdoost AA, Bahrampour A, Dehghani M. Modeling the burden of cardiovascular diseases in Iran from 2005 to 2025: The impact of demographic changes. Iran J Public Health. 2017;46(4):506.

3. Organization WH, Group ISoHW. 2003 World Health Organization (WHO)/International Society of Hypertension (ISH) statement on management of hypertension. J Hypertens. 2003;21(11):1983-92.

4. Murray CJ, et al. Effectiveness and costs of interventions to lower systolic blood pressure and cholesterol: a global and regional analysis on reduction of cardiovascular-disease risk. Lancet. 2003;361(9359):717-25. 
5. Darbandi M, Pasdar Y, Moradi S, Mohamed HJJ, Hamzeh B, Salimi Y. Discriminatory Capacity of Anthropometric Indices for Cardiovascular Disease in Adults: A Systematic Review and Meta-Analysis. Prev Chronic Dis. 2020;17:E131.

6. Cure $E$, et al. Atherogenic index of plasma: a useful marker for subclinical atherosclerosis in ankylosing spondylitis. Clin Rheumatol. 2018;37(5):1273-80.

7. Kouli G-M, et al. Visceral adiposity index and 10-year cardiovascular disease incidence: the ATTICA study. Nutr Metab Cardiovasc Dis. 2017;27(10):881-9.

8. Amato MC, et al. Visceral Adiposity Index: a reliable indicator of visceral fat function associated with cardiometabolic risk. Diabetes care. 2010;33(4):920-2.

9. Baveicy K, Mostafaei S, Darbandi M, Hamzeh B, Najafi F, Pasdar Y. Predicting Metabolic Syndrome by Visceral Adiposity Index, Body Roundness Index and a Body Shape Index in Adults: A Cross-Sectional Study from the Iranian RaNCD Cohort Data. Diabetes Metab Syndr Obes. 2020;13:879.

10. Nusrianto R, et al. Visceral adiposity index and lipid accumulation product as a predictor of type 2 diabetes mellitus: the Bogor cohort study of non-communicable diseases risk factors. Diabetes Res Clin Pract. 2019;155:107798.

11. Zhang Z, et al. Visceral adiposity index (VAI), a powerful predictor of incident hypertension in prehypertensives. Intern Emerg Med. 2018;13(4):509-16.

12. Nansseu JRN, Moor VJA, Nouaga MED, Zing-Awona B, Tchanana G, Ketcha A. Atherogenic index of plasma and risk of cardiovascular disease among Cameroonian postmenopausal women. Lipids Health Dis. 2016;15(1):1-5.

13. Niroumand S, et al. Atherogenic Index of Plasma (AIP): A marker of cardiovascular disease. Med J Islam Repub Iran. 2015;29:240.

14. Nwagha U, Ikekpeazu E, Ejezie F, Neboh E, Maduka I. Atherogenic index of plasma as useful predictor of cardiovascular risk among postmenopausal women in Enugu, Nigeria. Afr Health Sci. 2010;10(3).

15. Javardi MSM, Madani Z, Movahedi A, Karandish M, Abbasi B. The correlation between dietary fat quality indices and lipid profile with Atherogenic index of plasma in obese and non-obese volunteers: a crosssectional descriptive-analytic case-control study. Lipids Health Dis. 2020;19(1):1-9.

16. Ebrahimi R, et al. Low level of adiponectin predicts the development of Nonalcoholic fatty liver disease: Is it irrespective to visceral adiposity index, visceral adipose tissue thickness and other obesity indices? Arch Physiol Biochem. 2019:1-8.

17. Janghorbani M, Salamat MR, Aminorroaya A, Amini M. Utility of the visceral adiposity index and hypertriglyceridemic waist phenotype for predicting incident hypertension. Endocr Metab. 2017;32(2):221-9.

18. Ehsani B, Moslehi N, Mirmiran P, Tehrani FR, Tahmasebinejad Z, Azizi F. A visceral adiposity index-related dietary pattern and the cardiometabolic profiles in women with polycystic ovary syndrome. Clin Nutr. 2016;35(5):1181-7.

19. Pasdar Y, et al. Cohort profile: Ravansar Non-Communicable Disease cohort study: the first cohort study in a Kurdish population. International journal of epidemiology. 2019;48(3):682-3f.

20. Dobiasova M. AlP--atherogenic index of plasma as a significant predictor of cardiovascular risk: from research to practice. Vnitr Lek. 2006;52(1):64-71.

21. Nusrianto R, Tahapary DL, Soewondo P. Visceral adiposity index as a predictor for type 2 diabetes mellitus in Asian population: A systematic review. Diabetes Metab Syndr. 2019;13(2):1231-5. 
22. Janghorbani $M$, Amini $M$. The visceral adiposity index in comparison with easily measurable anthropometric markers did not improve prediction of diabetes. Can J Diabetes. 2016;40(5):393-8.

23. Qian W, Zheng D, Liu J, Li F, Li Q. Atherogenic index of plasma is a novel predictor of non-alcoholic fatty liver disease in obese participants: a cross-sectional study. Lipids Health Dis. 2018;17(1):1-6.

24. Bo MS, Cheah WL, Lwin S, Moe Nwe T, Win TT, Aung M. Understanding the relationship between atherogenic index of plasma and cardiovascular disease risk factors among staff of an University in Malaysia. J Nutr Metab. 2018;2018(3):1-6.

25. Zhu X, et al. Atherogenic index of plasma is a novel and better biomarker associated with obesity: a population-based cross-sectional study in China. Lipids Health Dis. 2018;17(1):1-6.

26. Saklayen MG. The global epidemic of the metabolic syndrome. Curr Hypertens Rep. 2018;20(2):12.

27. Yarahmadi S, Etemad K, Hazaveh AM, Azhang N. Urbanization and non-communicable risk factors in the capital city of 6 big provinces of Iran. Iran J Public Health. 2013;42(Supple1):113.

28. Kelishadi R, Alikhani S, Delavari A, Alaedini F, Safaie A, Hojatzadeh E. Obesity and associated lifestyle behaviours in Iran: findings from the first national non-communicable disease risk factor surveillance survey. Public Health Nutr. 2008;11(3):246-51.

29. Neeland IJ, et al. Dysfunctional adiposity and the risk of prediabetes and type 2 diabetes in obese adults. JAMA. 2012;308(11):1150-9.

30. Bouchi R, et al. Indirect measure of visceral adiposity 'A Body Shape Index'(ABSI) is associated with arterial stiffness in patients with type 2 diabetes. BMJ Open Diabetes Res Care. 2016;4(1).

31. Krakauer NY, Krakauer JC. A new body shape index predicts mortality hazard independently of body mass index. PloS One. 2012;7(7):e39504.

\section{Tables}

Table 1- Baseline characteristics according to cardiovascular disease (CVDs) status 


\begin{tabular}{|c|c|c|c|c|}
\hline Parameters & $\begin{array}{l}\text { Total } \\
(n=7362)\end{array}$ & $\begin{array}{l}\text { Non-CVDs } \\
(n=6191)\end{array}$ & $\begin{array}{l}\text { CVDs } \\
(n=1171)\end{array}$ & $P$ value \\
\hline Gender, Male, n (\%) & $3420(46.45)$ & $3036(49.04)$ & 384 (32.79) & $<0.001$ \\
\hline Age (year) & $47.20 \pm 8.33$ & $46.03 \pm 7.90$ & $53.39 \pm 7.79$ & $<0.001$ \\
\hline Current smoker, n (\%) & $865(22.33)$ & 764 (23.45) & $101(16.40)$ & $<0.001$ \\
\hline $\mathrm{BMI}\left(\mathrm{kg} / \mathrm{m}^{2}\right)$ & $27.44 \pm 4.67$ & $27.20 \pm 4.63$ & $28.69 \pm 4.66$ & $<0.001$ \\
\hline WHR & $0.94 \pm 0.06$ & $0.93 \pm 0.06$ & $0.95 \pm 0.06$ & $<0.001$ \\
\hline WC (cm) & $96.92 \pm 10.55$ & $96.28 \pm 10.43$ & $100.30 \pm 10.59$ & $<0.001$ \\
\hline BFM (kg) & $24.99 \pm 9.62$ & $24.42 \pm 9.54$ & $27.99 \pm 9.45$ & $<0.001$ \\
\hline PBF & $33.82 \pm 9.58$ & $33.09 \pm 9.56$ & $37.69 \pm 8.73$ & $<0.001$ \\
\hline $\operatorname{VFA}\left(\mathrm{cm}^{2}\right)$ & $121.93 \pm 51.83$ & $118.18 \pm 51.29$ & $141.71 \pm 50.13$ & $<0.001$ \\
\hline SLM (kg) & $3085(41.90)$ & $45.49 \pm 9.07$ & $42.82 \pm 8.40$ & $<0.001$ \\
\hline VAI (male) & $4.44 \pm 3.60$ & $4.37 \pm 3.60$ & $4.84 \pm 3.60$ & $<0.001$ \\
\hline VAI (female) & $6.54 \pm 5.31$ & $6.43 \pm 5.30$ & $7.13 \pm 5.30$ & $<0.001$ \\
\hline AIP & $0.97 \pm 0.65$ & $0.94 \pm 0.65$ & $1.07 \pm 0.61$ & $<0.001$ \\
\hline TG (mg/dl) & $136.61 \pm 84.00$ & $134.16 \pm 83.05$ & $149.57 \pm 87.78$ & $<0.001$ \\
\hline HDL-C (mg/dl) & $46.40 \pm 11.35$ & $46.41 \pm 11.36$ & $46.36 \pm 11.27$ & 0.555 \\
\hline LDL-C (mg/dl) & $101.86 \pm 25.42$ & $101.55 \pm 25.19$ & $103.51 \pm 26.55$ & 0.007 \\
\hline T-C (mg/dl) & $185.11 \pm 38.10$ & $184.54 \pm 37.64$ & $188.13 \pm 40.24$ & 0.003 \\
\hline FBS (mg/dl) & $96.94 \pm 30.05$ & $94.83 \pm 27.13$ & $108.11 \pm 40.47$ & $<0.001$ \\
\hline ALP (UI/L) & $197.11 \pm 61.02$ & $194.46 \pm 56.52$ & $211.13 \pm 79.29$ & $<0.001$ \\
\hline AST (Ul/L) & $21.43 \pm 8.95$ & $21.47 \pm 9.06$ & $21.20 \pm 8.36$ & 0.325 \\
\hline ALT (UI/L) & $24.70 \pm 14.28$ & $24.84 \pm 14.53$ & $23.94 \pm 12.88$ & 0.045 \\
\hline GGT (UI/L) & $24.30 \pm 18.89$ & $23.86 \pm 18.58$ & $26.63 \pm 20.30$ & $<0.001$ \\
\hline Hypertension, n (\%) & $1351(18.35)$ & $411(6.64)$ & $940(80.27)$ & $<0.001$ \\
\hline Dyslipidemia, n (\%) & $3085(41.90)$ & $2567(41.46)$ & $518(44.24)$ & 0.078 \\
\hline Metabolic syndrome, n (\%) & $1891(25.69)$ & $1261(20.37)$ & $630(53.80)$ & $<0.001$ \\
\hline \multicolumn{5}{|c|}{$\begin{array}{l}\text { AIP: Atherogenic index of plasma ; AST: Aspartate transaminase; ALT: Alanine aminotransferase; ALP: Alkaline } \\
\text { phosphatase; GGT: Gamma-glutamyl transferase;BFM: Body fat mass; PBF: Percent body fat; BMI: Body mass } \\
\text { index; CVD: Cardiovascular diseases; SLM: Skeletal muscle mass; FBS: Fasting blood sugar; TG: Triglycerides; } \\
\text { T- C: Total cholesterol; VAl: Visceral Adiposity Index; WC: Waist circumference; WHR: Waist hip ratio; VFA: } \\
\text { Visceral fat area }\end{array}$} \\
\hline
\end{tabular}


Table 2- Baseline Characteristics according to tertiles of visceral adiposity index (VAl) and atherogenic index of plasma (AIP) among by sex 


\begin{tabular}{|c|c|c|c|c|c|c|c|c|}
\hline \multirow[t]{3}{*}{ Parameters } & \multicolumn{8}{|c|}{ Tertiles of Visceral Adiposity Index } \\
\hline & \multicolumn{4}{|l|}{ Male } & \multicolumn{4}{|l|}{ Female } \\
\hline & $\begin{array}{l}\text { T1 }(n= \\
2051)\end{array}$ & $\begin{array}{l}\text { T2 }(n= \\
2760)\end{array}$ & $\begin{array}{l}\text { T3 }(n= \\
2551)\end{array}$ & $\begin{array}{l}P \\
\text { value }\end{array}$ & $\begin{array}{l}\text { T1 }(n= \\
795)\end{array}$ & $\begin{array}{l}\text { T2 }(n= \\
2309)\end{array}$ & $\begin{array}{l}\text { T3 }(n= \\
4258)\end{array}$ & $\begin{array}{l}P \\
\text { value }\end{array}$ \\
\hline Age (year) & $\begin{array}{l}46.36 \pm \\
8.39\end{array}$ & $\begin{array}{l}47.52 \pm \\
8.39\end{array}$ & $\begin{array}{l}47.52 \pm \\
8.19\end{array}$ & $<0.001$ & $\begin{array}{l}45.82 \pm \\
8.31\end{array}$ & $\begin{array}{l}46.99 \pm \\
8.37\end{array}$ & $\begin{array}{l}47.58 \pm \\
8.28\end{array}$ & $<0.001$ \\
\hline BMI $\left(\mathrm{kg} / \mathrm{m}^{2}\right)$ & $25.82 \pm 4.70$ & $\begin{array}{l}27.75 \pm \\
4.77\end{array}$ & $\begin{array}{l}28.40 \pm \\
4.17\end{array}$ & $<0.001$ & $\begin{array}{l}24.80 \pm \\
4.43\end{array}$ & $\begin{array}{l}26.89 \pm \\
4.81\end{array}$ & $\begin{array}{l}28.22 \pm \\
4.40\end{array}$ & $<0.001$ \\
\hline WHR & $0.91 \pm 0.06$ & $\begin{array}{l}0.94 \pm \\
0.06\end{array}$ & $\begin{array}{l}0.95 \pm \\
0.06\end{array}$ & $<0.001$ & $\begin{array}{l}0.90 \pm \\
0.06\end{array}$ & $\begin{array}{l}0.93 \pm \\
0.06\end{array}$ & $0.95 \pm 0.06$ & $<0.001$ \\
\hline WC (cm) & $\begin{array}{l}92.63 \pm \\
10.98\end{array}$ & $\begin{array}{l}97.62 \pm \\
10.49\end{array}$ & $\begin{array}{l}99.62 \pm \\
9.13\end{array}$ & $<0.001$ & $\begin{array}{l}90.01 \pm \\
10.79\end{array}$ & $\begin{array}{l}95.26 \pm \\
10.72\end{array}$ & $99.12 \pm 9.66$ & $<0.001$ \\
\hline TG (mg/dl) & $\begin{array}{l}70.50 \pm \\
18.93\end{array}$ & $\begin{array}{l}114.35 \pm \\
25.55\end{array}$ & $\begin{array}{l}213.83 \pm \\
96.73\end{array}$ & $<0.001$ & $\begin{array}{l}56.08 \pm \\
14.50\end{array}$ & $\begin{array}{l}88.39 \pm \\
19.74\end{array}$ & $\begin{array}{l}177.79 \pm \\
88.22\end{array}$ & $<0.001$ \\
\hline $\begin{array}{l}\mathrm{HDL}-\mathrm{C} \\
(\mathrm{mg} / \mathrm{dl})\end{array}$ & $\begin{array}{l}55.89 \pm \\
11.31\end{array}$ & $\begin{array}{l}46.49 \pm \\
8.60\end{array}$ & $\begin{array}{l}38.67 \pm \\
7.54\end{array}$ & $<0.001$ & $\begin{array}{l}60.64 \pm \\
12.00\end{array}$ & $\begin{array}{l}50.93 \pm \\
9.58\end{array}$ & $\begin{array}{l}41.28 \pm \\
8.42\end{array}$ & $<0.001$ \\
\hline $\begin{array}{l}\text { LDL-C } \\
(\mathrm{mg} / \mathrm{dl})\end{array}$ & $\begin{array}{l}92.85 \pm \\
23.03\end{array}$ & $\begin{array}{l}102.93 \pm \\
24.56\end{array}$ & $\begin{array}{l}107.95 \pm \\
26.14\end{array}$ & $<0.001$ & $\begin{array}{l}88.63 \pm \\
21.54\end{array}$ & $\begin{array}{l}97.52 \pm \\
24.35\end{array}$ & $\begin{array}{l}106.69 \pm \\
25.37\end{array}$ & $<0.001$ \\
\hline $\mathrm{T}-\mathrm{C}(\mathrm{mg} / \mathrm{dl})$ & $\begin{array}{l}173.74 \pm \\
34.56\end{array}$ & $\begin{array}{l}184.76 \pm \\
36.43\end{array}$ & $\begin{array}{l}194.63 \pm \\
39.97\end{array}$ & $<0.001$ & $\begin{array}{l}170.48 \pm \\
32.71\end{array}$ & $\begin{array}{l}178.15 \pm \\
36.26\end{array}$ & $\begin{array}{l}191.61 \pm \\
38.57\end{array}$ & $<0.001$ \\
\hline FBS (mg/dl) & $\begin{array}{l}91.33 \pm \\
24.40\end{array}$ & $\begin{array}{l}95.94 \pm \\
28.58\end{array}$ & $\begin{array}{l}102.54 \pm \\
34.45\end{array}$ & $<0.001$ & $\begin{array}{l}90.49 \pm \\
23.55\end{array}$ & $\begin{array}{l}92.94 \pm \\
25.79\end{array}$ & $\begin{array}{l}100.31 \pm \\
32.70\end{array}$ & $<0.001$ \\
\hline $\begin{array}{l}\text { Hypertension, } \\
\mathrm{n}(\%)\end{array}$ & $\begin{array}{l}253 \\
(18.73)\end{array}$ & $\begin{array}{l}558 \\
(41.30)\end{array}$ & $\begin{array}{l}540 \\
(39.97)\end{array}$ & $<0.001$ & $78(5.77)$ & $\begin{array}{l}368 \\
(27.24)\end{array}$ & $\begin{array}{l}905 \\
(66.99)\end{array}$ & $<0.001$ \\
\hline $\begin{array}{l}\text { Dyslipidemia, } \\
\text { n (\%) }\end{array}$ & $169(5.48)$ & $\begin{array}{l}824 \\
(26.71)\end{array}$ & $\begin{array}{l}2092 \\
(67.81)\end{array}$ & $<0.001$ & $29(0.94)$ & $\begin{array}{l}362 \\
(11.73)\end{array}$ & $\begin{array}{l}2694 \\
(87.33)\end{array}$ & $<0.001$ \\
\hline $\begin{array}{l}\text { Metabolic } \\
\text { syndrome, n } \\
(\%)\end{array}$ & $\begin{array}{l}269 \\
(14.23)\end{array}$ & $\begin{array}{l}572 \\
(30.25)\end{array}$ & $\begin{array}{l}1050 \\
(55.53)\end{array}$ & $<0.001$ & $88(4.65)$ & $\begin{array}{l}355 \\
(18.77)\end{array}$ & $\begin{array}{l}1448 \\
(76.57)\end{array}$ & $<0.001$ \\
\hline CVD, n (\%) & $\begin{array}{l}235 \\
(20.07)\end{array}$ & $\begin{array}{l}471 \\
(40.22)\end{array}$ & $\begin{array}{l}465 \\
(39.71)\end{array}$ & $<0.001$ & 70 (5.98) & $\begin{array}{l}336 \\
(28.69)\end{array}$ & $\begin{array}{l}765 \\
(65.33)\end{array}$ & $<0.001$ \\
\hline \multicolumn{9}{|c|}{ Tertiles of Atherogenic index of plasma } \\
\hline & $\begin{array}{l}\text { T1 }(n= \\
866)\end{array}$ & $\begin{array}{l}\text { T2 }(n= \\
1119)\end{array}$ & $\begin{array}{l}\text { T3 }(n= \\
1435)\end{array}$ & $\begin{array}{l}P \\
\text { value }\end{array}$ & $\begin{array}{l}\mathrm{T} 1 \\
(\mathrm{n}=1588)\end{array}$ & $\begin{array}{l}\text { T2 }(n= \\
1335)\end{array}$ & $\begin{array}{l}\text { T3 }(n= \\
1019)\end{array}$ & $\begin{array}{l}P \\
\text { value }\end{array}$ \\
\hline Age (year) & $\begin{array}{l}46.98 \pm \\
8.37\end{array}$ & $\begin{array}{l}46.81 \pm \\
8.23\end{array}$ & $\begin{array}{l}46.42 \pm \\
7.88\end{array}$ & 0.0 & $\begin{array}{l}46.56 \pm \\
8.52\end{array}$ & $\begin{array}{l}48.07 \pm \\
8.35\end{array}$ & $48.73 \pm 8.41$ & $<0.001$ \\
\hline BMI $\left(\mathrm{kg} / \mathrm{m}^{2}\right)$ & $23.99 \pm 388$ & $\begin{array}{l}26.07 \pm \\
3.89\end{array}$ & $\begin{array}{l}27.64 \pm \\
3.65\end{array}$ & $<0.001$ & $\begin{array}{l}27.04 \pm \\
4.81\end{array}$ & $\begin{array}{l}29.29 \pm \\
4.83\end{array}$ & $\begin{array}{l}19.74 \pm \\
4.53\end{array}$ & $<0.001$ \\
\hline WHR & $0.90 \pm 0.06$ & $\begin{array}{l}0.94 \pm \\
0.06\end{array}$ & $\begin{array}{l}0.96 \pm \\
0.06\end{array}$ & $<0.001$ & $\begin{array}{l}0.93 \pm \\
0.06\end{array}$ & $\begin{array}{l}0.95 \pm \\
0.05\end{array}$ & $0.96 \pm 0.05$ & $<0.001$ \\
\hline WC (cm) & $\begin{array}{l}91.54 \pm \\
9.66\end{array}$ & $\begin{array}{l}95.58 \pm \\
9.61\end{array}$ & $\begin{array}{l}98.45 \pm \\
8.67\end{array}$ & $<0.001$ & $\begin{array}{l}95.12 \pm \\
11.63\end{array}$ & $\begin{array}{l}99.44 \pm \\
10.89\end{array}$ & $\begin{array}{l}100.36 \pm \\
9.86\end{array}$ & $<0.001$ \\
\hline
\end{tabular}




\begin{tabular}{|c|c|c|c|c|c|c|c|c|}
\hline $\mathrm{TG}(\mathrm{mg} / \mathrm{dl})$ & $\begin{array}{l}70.73 \pm \\
18.62\end{array}$ & $\begin{array}{l}112.96 \pm \\
22.88\end{array}$ & $\begin{array}{l}216.34 \pm \\
95.55\end{array}$ & $<0.001$ & $\begin{array}{l}75.75 \pm \\
20.71\end{array}$ & $\begin{array}{l}123.99 \pm \\
25.59\end{array}$ & $\begin{array}{l}217.64 \pm \\
99.69\end{array}$ & $<0.001$ \\
\hline $\begin{array}{l}\text { HDL-C } \\
\text { (mg/dl) }\end{array}$ & $\begin{array}{l}51.67 \pm \\
10.68\end{array}$ & $\begin{array}{l}43.21 \pm \\
7.23\end{array}$ & $\begin{array}{l}36.80 \pm \\
6.89\end{array}$ & $<0.001$ & $\begin{array}{l}56.66 \pm \\
11.04\end{array}$ & $\begin{array}{l}48.06 \pm \\
8.61\end{array}$ & $\begin{array}{l}40.78 \pm \\
7.69\end{array}$ & $<0.001$ \\
\hline $\begin{array}{l}\text { LDL-C } \\
(\mathrm{mg} / \mathrm{dl})\end{array}$ & $\begin{array}{l}91.74 \pm \\
23.69\end{array}$ & $\begin{array}{l}101.39 \pm \\
23.69\end{array}$ & $\begin{array}{l}106.02 \pm \\
24.59\end{array}$ & $<0.001$ & $\begin{array}{l}94.83 \pm \\
23.52\end{array}$ & $\begin{array}{l}105.86 \pm \\
24.33\end{array}$ & $\begin{array}{l}110.85 \pm \\
28.29\end{array}$ & $<0.001$ \\
\hline T-C (mg/dl) & $\begin{array}{l}169.27 \pm \\
34.17\end{array}$ & $\begin{array}{l}178.96 \pm \\
34.12\end{array}$ & $\begin{array}{l}190.30 \pm \\
37.54\end{array}$ & $<0.001$ & $\begin{array}{l}177.58 \pm \\
35.34\end{array}$ & $\begin{array}{l}191.42 \pm \\
36.62\end{array}$ & $\begin{array}{l}201.46 \pm \\
42.75\end{array}$ & $<0.001$ \\
\hline $\mathrm{FBS}(\mathrm{mg} / \mathrm{dl})$ & $\begin{array}{l}92.64 \pm \\
29.54\end{array}$ & $\begin{array}{l}96.24 \pm \\
29.13\end{array}$ & $\begin{array}{l}100.56 \pm \\
32.40\end{array}$ & $<0.001$ & $\begin{array}{l}91.39 \pm \\
22.17\end{array}$ & $\begin{array}{l}97.38 \pm \\
29.64\end{array}$ & $\begin{array}{l}104.34 \pm \\
36.36\end{array}$ & $<0.001$ \\
\hline $\begin{array}{l}\text { Hypertension, } \\
\mathrm{n}(\%)\end{array}$ & 84 (9.70) & $\begin{array}{l}181 \\
(16.18)\end{array}$ & $\begin{array}{l}230 \\
(16.03)\end{array}$ & $<0.001$ & $\begin{array}{l}241 \\
(15.18)\end{array}$ & $\begin{array}{l}327 \\
(24.49)\end{array}$ & $\begin{array}{l}288 \\
(28.26)\end{array}$ & $<0.001$ \\
\hline $\begin{array}{l}\text { Dyslipidemia, } \\
\text { n (\%) }\end{array}$ & $\begin{array}{l}108 \\
(12.47)\end{array}$ & $\begin{array}{l}424 \\
(37.89)\end{array}$ & $\begin{array}{l}1248 \\
(86.97)\end{array}$ & $<0.001$ & $\begin{array}{l}134 \\
(8.44)\end{array}$ & $\begin{array}{l}355 \\
(26.59)\end{array}$ & $\begin{array}{l}816 \\
(80.08)\end{array}$ & $<0.001$ \\
\hline $\begin{array}{l}\text { Metabolic } \\
\text { syndrome, n } \\
(\%)\end{array}$ & $\begin{array}{l}100 \\
(11.55)\end{array}$ & $\begin{array}{l}219 \\
(19.57)\end{array}$ & $\begin{array}{l}530 \\
(36.93)\end{array}$ & $<0.001$ & $\begin{array}{l}238 \\
(14.99)\end{array}$ & $\begin{array}{l}326 \\
(24.42)\end{array}$ & $\begin{array}{l}478 \\
(46.91)\end{array}$ & $<0.001$ \\
\hline CVD, n (\%) & 78 (9.01) & $\begin{array}{l}128 \\
(11.44)\end{array}$ & $\begin{array}{l}178 \\
(12.40)\end{array}$ & $<0.001$ & $\begin{array}{l}235 \\
(14.80)\end{array}$ & $\begin{array}{l}287 \\
(21.50)\end{array}$ & $\begin{array}{l}265 \\
(26.02)\end{array}$ & $<0.001$ \\
\hline
\end{tabular}

Table 3- Association of atherogenic index of plasma and visceral adiposity index with cardiovascular diseases, logistic regression analysis

\begin{tabular}{|c|c|c|c|c|c|c|}
\hline \multirow[t]{2}{*}{ Variables } & \multicolumn{2}{|l|}{ Model 1} & \multicolumn{2}{|l|}{ Model 2} & \multicolumn{2}{|l|}{ Model 3} \\
\hline & OR (95\% Cl) & $P$ value & OR $(95 \% \mathrm{Cl})$ & $P$ value & OR $(95 \% \mathrm{Cl})$ & $P$ value \\
\hline AIP : T1 & 1.00 (Reference) & & 1.00 (Reference) & & 1.00 (Reference) & \\
\hline T2 & $1.39(1.19,1.63)$ & $<0.001$ & $1.23(1.10,1.57)$ & 0.003 & $1.27(1.06,1.52)$ & 0.008 \\
\hline T3 & $1.51(1.28,1.76)$ & $<0.001$ & $1.47(1.38,1.95)$ & $<0.001$ & $1.63(1.31,2.03)$ & $<0.001$ \\
\hline VAl:T1 & 1.00 (Reference) & & 1.00 (Reference) & & 1.00 (Reference) & \\
\hline T2 & $1.48(1.26,1.74)$ & $<0.001$ & $1.43(1.19,1.71)$ & $<0.001$ & $1.41(1.18,1.70)$ & $<0.001$ \\
\hline T3 & $1.80(1.54,2.11)$ & $<0.001$ & $1.91(1.59,2.29)$ & $<0.001$ & $1.98(1.60,2.46)$ & $<0.001$ \\
\hline \multicolumn{7}{|c|}{$\begin{array}{l}\text { * Model 1: Unadjusted; Model 2: Adjusted for age and sex, Model 3: Adjusted for age, sex, hypertension, } \\
\text { dyslipidemia }\end{array}$} \\
\hline \multicolumn{7}{|c|}{ AIP: Atherogenic index of plasma, VAI: Visceral Adiposity Index, T: tertile } \\
\hline
\end{tabular}

\section{Figures}



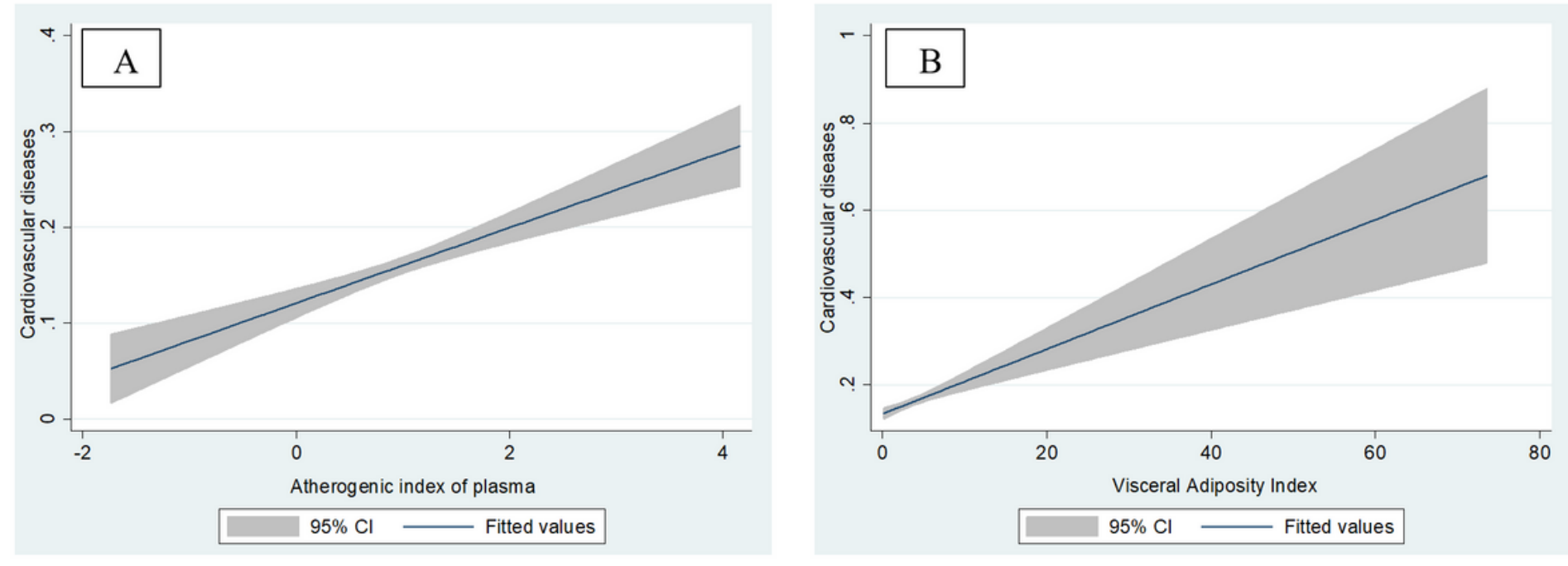

\section{Figure 1}

Associations atherogenic index of plasma (A) and visceral adiposity index (B) with cardiovascular diseases 